\title{
Universality classes and critical phenomena in confined liquid systems
}

\author{
A.V. Chaly $1^{1}$, L.A. Bulavin ${ }^{2}$, V.F. Chekhun ${ }^{\frac{3}{3}}$, K.A. Chaly $y^{1}$, L.M. Chernenko ${ }^{4}$, \\ A.M. Vasilev ${ }^{2}$, E.V. Zaitseva ${ }^{1}$, G.V. Khrapijchyk ${ }^{1}$, A.V. Siverin ${ }^{2}$, M.V. Kovalenko ${ }^{2}$ \\ ${ }^{1}$ Bogomolets National Medical University, Kyiv, Ukraine \\ 2 Taras Shevchenko Kiev National University, Kyiv, Ukraine \\ ${ }^{3}$ Kavetskii Institute of Experimental Pathology, Oncology and Radiobiology, \\ National Academy of Sciences of Ukraine \\ ${ }^{4}$ Chuiko Institute of Surface Chemistry, National Academy of Sciences of Ukraine
}

Received April 17, 2013, in final form May 17, 2013

\begin{abstract}
It is well known that the similar universal behavior of infinite-size (bulk) systems of different nature requires the same basic conditions: space dimensionality; number components of order parameter; the type (short- or longrange) of the intermolecular interaction; symmetry of the fluctuation part of thermodynamical potential. Basic conditions of similar universal behavior of confined systems needs the same supplementary conditions such as the number of monolayers for a system confinement; low crossover dimensionality, i.e., geometric form of restricted volume; boundary conditions on limiting surfaces; physical properties under consideration. This review paper is aimed at studying all these conditions of similar universal behavior for diffusion processes in confined liquid systems. Special attention was paid to the effects of spatial dispersion and low crossover dimensionality. This allowed us to receive receiving correct nonzero expressions for the diffusion coefficient at the critical point and to take into account the specific geometric form of the confined liquid volume. The problem of 3D $\Leftrightarrow 2 D$ dimensional crossover was analyzed. To receive a smooth crossover for critical exponents, the Kawasaki-like approach from the theory of mode coupling in critical dynamics was proposed. This ensured a good agreement between data of computer experiment and theoretical calculations of the size dependence of the critical temperature $T_{\mathrm{c}}(H)$ of water in slitlike pores. The width of the quasi-elastic scattering peak of slow neutrons near the structural phase transition in the aquatic suspensions of plasmatic membranes (mesostructures with the typical thickness up to $10 \mathrm{~nm}$ ) was studied. It was shown that the width of quasi-elastic peak of neutron scattering decreases due to the process of cell proliferation, i.e., with an increase of the membrane size (including the membrane thickness). Thus, neutron studies could serve as an additional diagnostic test for the process of tumor formation.
\end{abstract}

Key words: universality classes, confined liquid systems, spatial dispersion, low crossover dimensionality, dimensional crossover, width of quasi-elastic peak, neutron scattering

PACS: 05.70.Jk, 68.18.Jk, 68.35.Rh, 61.12.-q, 82.56.Lz

\section{Introduction}

Second half of the previous century, especially its last decades, was guided by two great achievements of experimental and theoretical physics: (i) the revolutionary discoveries in nanotechnologies, (ii) solution of problem of the $2^{\text {nd }}$ order phase transitions. It is now considered generally accepted that the achievements of nanosciences (including nanoelectronics and nanomedicine) will determine the character of the $21^{\text {th }}$ century. It is difficult to overestimate the consequences of creation of modern picture of physics of phase transitions and critical phenomena (physics of cooperative processes) based on precise experiments and profound ideas of scale invariance (scaling) and renormalization group [1-3] as well as of the method of collective variables [4, 5]. Unification of these two directions in the development of physics, which started 40 years ago following the formulation of the scaling hypothesis for spatially 
limited systems [6-8], continues to raise an increasing interest of researchers to the study of phase transitions and critical phenomena in mesoscale systems. In resent years this interest touches not only upon magnetics and liquid crystals but also extends to low- and high- temperature liquid systems.

The ideas of isomorphism of critical phenomena and phase transitions [9, 10] make it possible to generalize the properties of confined liquids to the systems not only of physical but also of other nature.

This review paper is aimed at studying the conditions of similar universal behavior in confined liquids. Its structure is as follows. Section 2 "Discussion" consists of three subsections. The $1^{\text {st }}$ subsection is devoted to the universal behavior of bulk and finite-size systems of different nature. In the $2^{\text {nd }}$ subsection we consider the diffusion processes in mesoscale liquid systems with taking into account the additional factors of universality classes for finite-size systems, especially the spatial dispersion and the geometric form of finite-size volumes under consideration. The $3^{\text {rd }}$ subsection is devoted to our original studies of the dimensional crossover (or smooth transition) between the properties of the bulk 3D and finitesize (even 2D) systems. For this purpose we introduce the Kawasaki-like analytical expression for such a $3 D \Leftrightarrow 2 \mathrm{D}$ dimensional crossover and propose the theoretical background for the results of computer simulations with the interpolation formula for the effective critical exponent $v(H)$. And finally, in section 3 , we use the methods of neutron optics to study the temperature and size dependence of the width $\triangle E$ of the quasielastic neutron scattering peak near the structural phase transition in the plasmatic membranes (mesostructures with the typical thickness up to $10 \mathrm{~nm}$ ). It is shown that studies of the width $\triangle E$ of the quasielastic neutron scattering peak can be applied as an effective tool for the tumor growth diagnostics.

\section{Discussion}

\subsection{Universality classes for infinite (bulk) and finite-size systems}

Let us first recall the important notion of universality classes. Basic conditions of the similar universal behaviour for infinite-size (bulk) systems of different nature are well-known [1-3, 9, 10]: (i) space dimensionality; (ii) the number of components of order parameters; (iii) the type (short- or long-range) of the intermolecular interaction; (iv) symmetry of Hamiltonian (fluctuation part of the thermodynamic potential). Similar universal behaviour for confined systems needs the following basic conditions in addition to four previous ones: (v) geometric factors (the number of monolayers) for system confinement; (vi) low crossover dimensionality defined by the shape of the restricted volume, (see below for a more detailed explanation); (vii) the type of boundary conditions; (viii) the physical properties under consideration [68, 11-13]. These basic conditions of similar universal behavior of confined systems will be illustrated herein below.

\subsection{Diffusion processes in mesoscale liquid systems}

Methods of the theory of phase transitions in the spatially limited systems are used here to study the diffusion coefficient of water molecules in cylindrical pores, as well as the effects of spatial dispersion and low crossover dimensionality (geometrical form) on the diffusion processes [6-8, 11- 17].

Taking into account the fundamentals of thermodynamics and statistical physics of irreversible processes as well as the modern theory of critical phenomena in liquid systems, one can write down the coefficient of self-diffusion

$$
D=\left(L_{\mathrm{R}}+L_{\mathrm{S}}\right)(\partial \mu / \partial \rho)_{T} .
$$

Here, $L_{\mathrm{R}}$ and $L_{\mathrm{S}}$ are regular and singular parts of the kinetic Onsager coefficient, the derivative $(\partial \mu / \partial \rho)_{T}$ is proportional to the inverse value of the isothermal compressibility of liquids. In accordance with the theory of dynamic scaling, the singular part $L_{\mathrm{S}}$ of the Onsager coefficient behaves as the characteristic correlation length of the order parameter fluctuations (for liquids - fluctuations of density), namely: $L_{\mathrm{S}}=L_{\mathrm{S}}^{0}\left(\tau^{*}\right)^{-v}$ where $L_{\mathrm{S}}^{0}$ is the amplitude, $\tau^{*}$ is the corresponding temperature variable for the systems with restricted geometry, and $v \approx 0.63$ is the critical index. This value for the correlation length critical exponent $v$ is taken because the bulk classical liquids belong to the 3D Ising model universality class. According to the scaling theory, the derivative $(\partial \mu / \partial \rho)_{T}=(\partial \mu / \partial \rho)_{T}^{0}\left(\tau^{*}\right)^{\gamma}$. Here, $(\partial \mu / \partial \rho)_{T}^{0}$ is the amplitude of inverse isothermal compressibility, and $\gamma \approx 1.24$ is the isothermal compressibility critical index in the 
3D Ising model universality class. Finally, the coefficient of self-diffusion in the spatially-limited liquid system is described by the following formula:

$$
D=\left[L_{\mathrm{R}}+L_{\mathrm{S}}^{0}\left(\tau^{*}\right)^{-v}\right](\partial \mu / \partial \rho)_{T}^{0}\left(\tau^{*}\right)^{\gamma} .
$$

In a general case, while describing the dynamic phenomena, the following three regions exist depending on temperature "distance" to the phase transition point [18]:

1. Dynamic fluctuation region, where singular parts of kinetic Onsager coefficients substantially prevail over its regular parts $\left(L_{S} \gg L_{R}\right)$;

2. Dynamic crossover region, where both parts of the kinetic Onsager coefficients are of the same order of magnitude $\left(L_{\mathrm{S}} \approx L_{\mathrm{R}}\right)$;

3. Dynamic regular region, where singular parts of kinetic Onsager coefficients are substantially less than its regular parts $\left(L_{\mathrm{S}} \ll L_{\mathrm{R}}\right)$.

An answer to a question, which of these regions realize in experiments or in natural conditions, depends on the value of Ginzburg-Levanyuk number Gi, which permits to estimate the role of fluctuation effects. For weak aquatic solutions with $\mathrm{Gi} \approx 0.3$ only dynamic crossover and regular regions are expected to be observed in reality.

It appears that the temperature variable $\tau^{*}$ is characterized by the following formula in liquids with confined geometry [11, 16, 17]:

$$
\tau^{*}=(G / S)^{\frac{1}{v}}+\left[1+(G / S)^{\frac{1}{v}}\right]\left(\xi^{*}\right)^{-\frac{1}{v}} .
$$

Here, $G$ is a geometrical factor which depends on the low crossover dimensionality (geometrical form) of liquid volume [for the plane-parallel layer $G=\pi$, while for cylindrical sample $G=2.4048$ is the first zero of the Bessel function $J_{0}(z) ; S=L / a_{0}$ is the number of monolayers ( $L$ is a linear size of the system) in the direction of its spatial limitation, $a_{0}$ is the average diameter of a molecule], $\xi^{*}=\xi / \xi_{0}$ is the dimensionless correlation length of density fluctuations ( $\xi_{0}$ is the amplitude of correlation length which has the same order of magnitude as $a_{0}$ ).

The size dependence of the self-diffusion coefficient $D(S)$ is theoretically estimated in the dynamic crossover region in accordance with formulae (2.2), (2.3) in [15] (figures 1, 2). Obviously, in a general case of restricted systems for which inequality $\xi \gg L$ is correct, the first term $(G / S)^{\frac{1}{v}}$ will prevail in (2.3), that is why the diffusion coefficient will decrease at the fixed temperature while the linear sizes of a system increase. In the opposite case, i.e., for a relatively large linear size in the sense of inequality $\xi \ll L$, the multiplier $\left(\xi^{*}\right)^{-\frac{1}{v}}$ in the second term in (2.3) will play a greater role. That is why the diffusion coefficient $D$ will grow and will asymptotically approach the value of $D_{0}$ in the spatially unlimited volume.

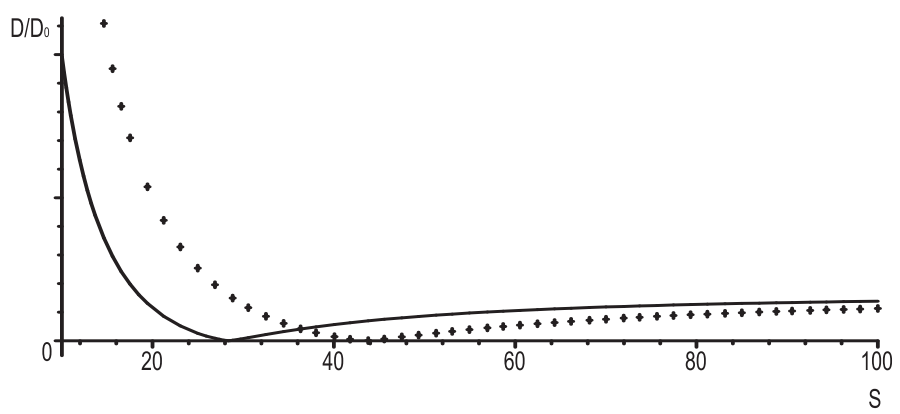

Figure 1. Dependence of self-diffusion coefficient $D$ on $S$.

Figure 1 illustrates a non-monotonous dependence of self-diffusion coefficient $D$ (in relative units) on the parameter $S$ (the curve with circles - for the liquid system with cylindrical geometry, dotted curve for geometry of plane-parallel layer), at the fixed temperature deviation $\tau=\left(T-T_{\mathrm{c}}\right) / T_{\mathrm{c}}=-0.01$, where $T_{\mathrm{c}}$ is the critical temperature of a bulk phase. 


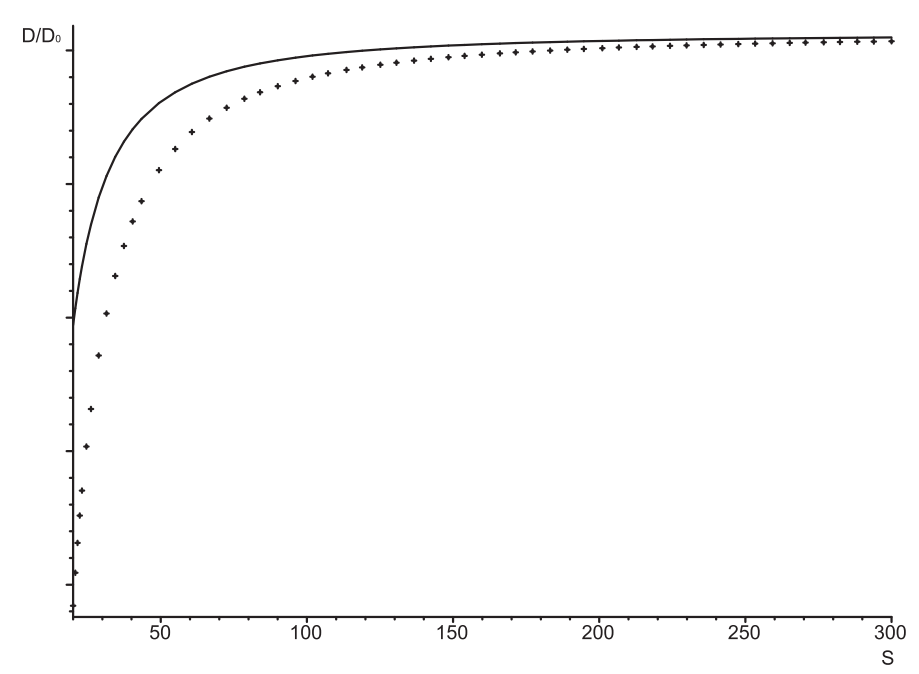

Figure 2. Size dependence of self-diffusion coefficient at $S \gg \xi^{*}$.

An increase of the self-diffusion coefficient $D$ with the growth of $S$ (see right-hand part of figure 1 at $S>40$, and figure 2), is confirmed both by experimental data [19] in cylindrical pores within the range interval of radius $40-150 \mathrm{~nm}$ and by theoretical calculations [13] for the self-diffusion coefficient of water molecules.

Table 1. Correspondence between the real system geometry and low crossover dimensionality $d_{\mathrm{LCD}}$.

\begin{tabular}{|c|c|c|}
\hline $\begin{array}{c}\text { Real 3-dimensional confined } \\
\text { systems }\end{array}$ & $\begin{array}{c}\text { A corresponding } \\
\text { borderline case }\end{array}$ & $\begin{array}{c}\text { Low crossover } \\
\text { dimensionality }\end{array}$ \\
\hline \hline $\begin{array}{c}\text { Plane-parallel layer, slitlike pore, } \\
\text { plane interphase, membrane, } \\
\text { synaptic cleft }\end{array}$ & $\begin{array}{c}\text { monomolecular } \\
\text { plane }\end{array}$ & 2 \\
\hline $\begin{array}{c}\text { Cylindrical pore, long pore with } \\
\text { square or rectangular sections, } \\
\text { ionic channel }\end{array}$ & $\begin{array}{c}\text { monomolecular } \\
\text { filament (line) }\end{array}$ & 1 \\
\hline $\begin{array}{c}\text { Sphere, cube, parallelepiped, } \\
\text { ellipsoid of rotation, vesicle }\end{array}$ & Point (one molecule) & 0 \\
\hline
\end{tabular}

Theoretical studies performed in [15] demonstrate the dependence of the self-diffusion coefficient on the geometric form of a liquid system or, in other words, on its low crossover dimensionality $d_{\mathrm{LCD}}$. This is briefly summarized in table 1 . The low crossover dimensionality $d_{\text {LCD }}$ determines the limited spatial dimension of geometric objects ( $2^{\text {nd }}$ column) towards which the real investigated system ( $1^{\text {st }}$ column) passes if its linear size (sizes) in the direction (directions) of spatial limitation converge to a minimum possible size, i.e., to the molecule diameter. It is clear that a three-dimensional plane-parallel layer transfers to the monomolecular plane (essentially - 2D object), while a three-dimensional cylindrical pore passes to the monomolecular filament (essentially -1D object), while spheres or cubes restricted at three directions have as its limit only one molecule, i.e., 0D object. The last $3^{\text {rd }}$ column of table 1 contains the value of $d_{\mathrm{LCD}}$ for real spatially limited systems.

The analysis of the dependence of the self-diffusion coefficient on $d_{\mathrm{LCD}}$ makes it possible to formulate the following conclusion valid for other equilibrium and non-equilibrium properties of nano- and mesoscale systems: with an increase of $d_{\mathrm{LCD}}$, physical properties of the spatially limited systems tend to their bulk values. 
Another conclusion concerns the temperature position $\tau_{\mathrm{M}}(S)=\left[T_{\mathrm{c}}(S)-T_{\mathrm{c}}\right] / T_{\mathrm{c}}$ of the extremum (precisely-minimum) of the self-diffusion coefficient depending on the parameter $S$, i.e., linear size $L$ of the liquid systems with different crossover dimensionalities.
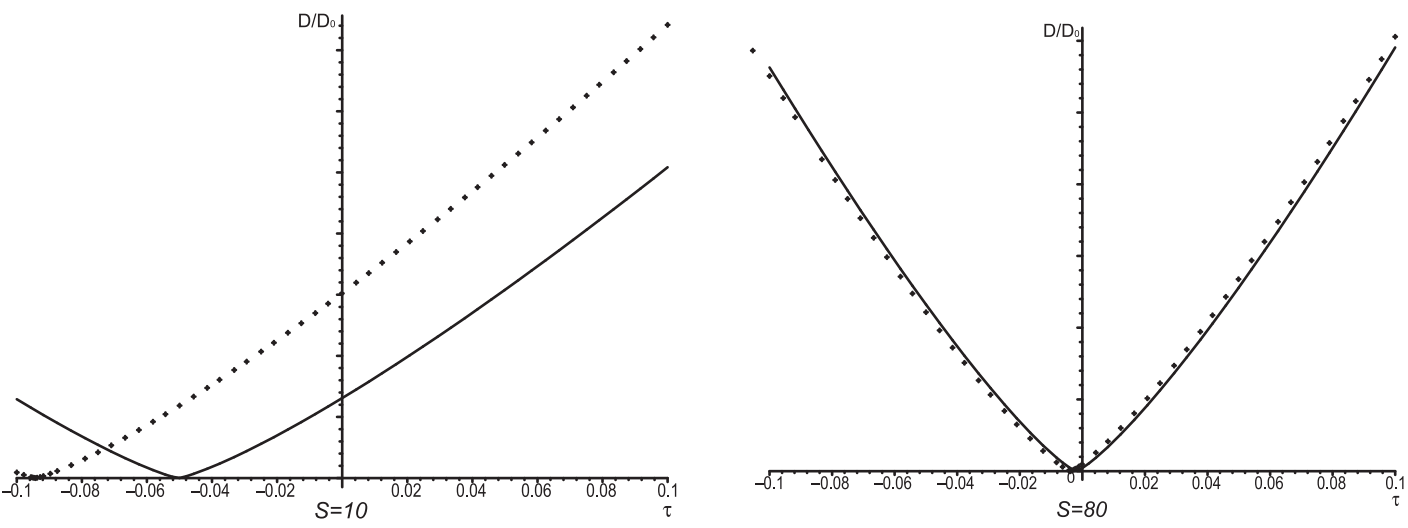

Figure 3. Dependence of the self-diffusion coefficient $D$ on $\tau=\left(T-T_{\mathrm{C}}\right) / T_{\mathrm{C}}$ at $S=$ const.

As it follows from figure 3 obtained in [15], the temperature deviation $\tau_{\mathrm{M}}(S)$ has a negative value (in complete accordance with the scaling theory for spatially-limited systems); increases modulo at diminishing the $d_{\mathrm{LCD}}$; and tends to zero at increasing the linear sizes of the system.

The above-mentioned results and conclusions are qualitatively confirmed by the data of the heat capacity temperature dependence in confined liquids of different geometry [20]. It follows that a heat capacity maximum shifts to the region of lower temperatures and this shift grows from a bulk phase to the liquids with $d_{\mathrm{LCD}}$ changing from 2 to 1 and 0 (see table 1 where the real examples of such spatially limited liquids are presented).

Table 2. Self-diffusion coefficient for water molecules and related properties (see text for the explanation).

\begin{tabular}{|c|c|c|c|c|c|c|}
\hline$\tau$ & $L_{\mathrm{R}}^{*}$ & $L_{\mathrm{S}}^{*}$ & $L^{*}$ & $(\partial \mu / \partial \rho)_{T}^{*}$ & $D^{*}$ & $D_{\text {water }} m^{2} / s$ \\
\hline \hline 1.0 & 1 & $10^{-3}$ & 1.001 & 1 & 1.001 & $2.30 \cdot 10^{-9}$ \\
\hline $10^{-1}$ & 1 & $4 \cdot 10^{-3}$ & 1.004 & $5.6 \cdot 10^{-2}$ & $5.622 \cdot 10^{-2}$ & $1.29 \cdot 10^{-10}$ \\
\hline $10^{-2}$ & 1 & $1.8 \cdot 10^{-2}$ & 1.018 & $3.3 \cdot 10^{-3}$ & $3.359 \cdot 10^{-3}$ & $7.73 \cdot 10^{-12}$ \\
\hline $10^{-3}$ & 1 & $10^{-1}$ & 1.1 & $1.9 \cdot 10^{-4}$ & $1.945 \cdot 10^{-4}$ & $4.47 \cdot 10^{-13}$ \\
\hline $10^{-4}$ & 1 & $3 \cdot 10^{-1}$ & 1.3 & $1.1 \cdot 10^{-5}$ & $1.43 \cdot 10^{-5}$ & $3.29 \cdot 10^{-14}$ \\
\hline $10^{-5}$ & 1 & 1 & 2.0 & $6.3 \cdot 10^{-7}$ & $1.26 \cdot 10^{-6}$ & $2.90 \cdot 10^{-15}$ \\
\hline $10^{-6}$ & 1 & 6.3 & 7.3 & $3.6 \cdot 10^{-8}$ & $2.63 \cdot 10^{-7}$ & $6.05 \cdot 10^{-16}$ \\
\hline $10^{-7}$ & 1 & 25 & 26 & $2.1 \cdot 10^{-9}$ & $5.46 \cdot 10^{-8}$ & $1.26 \cdot 10^{-16}$ \\
\hline
\end{tabular}

Analytical formulae obtained for the self-diffusion coefficient $D^{*}=D / D_{0}$ make it possible to conduct numeral calculations of the self-diffusion coefficient $D$ of a certain liquid almost in the whole critical area $(0 \leqslant \tau \leqslant 1)$ using only a single parameter, i.e., the known value of amplitude $D_{0}=L_{\mathrm{R}}^{0}(\partial \mu / \partial \rho)_{T}^{0}$. As an example, the results of self-diffusion coefficient for water molecules are presented in table 2 . The value of the amplitude of self-diffusion coefficient for water molecules $D_{0}$ used for this purpose was found in a regular area far from the critical point: $D_{0}=2.3 \cdot 10^{-9} \mathrm{~m}^{2} / \mathrm{s}$. This value was obtained experimentally for the molecules of water at the temperature of $T=293 \mathrm{~K}$, which corresponds to the temperature deviation $\tau \approx-0.5$ from the critical temperature of water of $T_{\mathrm{c}}=647 \mathrm{~K}$. Then, taking into account the value of $D_{0}$, as well as data for $D^{*}$ from the next to the last column of table 2, we get numerical results for temperature dependence of the diffusion coefficient of water molecules in the critical region (see the last column of table 2).

The effects of spatial dispersion (nonlocality) being neglected results in the physical properties in 
the critical points or the points of the 2nd order phase transitions tending to infinity (i.e., isothermal compressibility, magnetic susceptibility, isobar and isochoric heat capacities and others) or to zero (i.e., coefficients of diffusion and thermal diffusivity, speed of sound and others). To take into account the effects of spatial dispersion, the following idea is used [21]: spatial dispersion terms must be added to the values which become equal to zero in the critical point (for example, added to the coefficient of diffusion of $D$ or to the reverse value of the isothermal compressibility). Thus, for the self-diffusion coefficient one has the following formula:

$$
D^{*}\left(\xi^{*}, S, k\right)=\frac{\left\{(G / S)^{\frac{1}{v}}+\left[1+(G / S)^{\frac{1}{v}}\right]\left(\xi^{*}\right)^{-\frac{1}{v}} \operatorname{sign} \tau\right\}^{\gamma}+B k^{2}}{\left\{(G / S)^{\frac{1}{v}}+\left[1+(G / S)^{\frac{1}{v}}\right]\left(\xi^{*}\right)^{-\frac{1}{v}} \operatorname{sign} \tau\right\}^{v}+b k^{2}} .
$$

It follows from (2.4) that a minimum nonzero value of the diffusion coefficient is equal to

$$
D_{\min }^{*}(L)=\frac{(G / S)^{\frac{\gamma}{v}}+4 \pi^{2} B / L^{2}}{(G / S)^{\frac{\gamma}{v}}+4 \pi^{2} b / L^{2}} .
$$

The same approach could be also used for taking into account the effects of temporal (frequency) dispersion of physical properties in the critical region. However, this problem will not be examined herein.

In the critical point $(\tau=0$ ), the self-diffusion coefficient of the bulk phase is constant and nonzero: $D=$ $L_{\mathrm{R}}^{0}(\partial \mu / \partial \rho)_{T}^{0} B / b=$ const where $B$ and $b$ are coefficients of nonlocality. Figure 4 (solid curve) illustrates this result. Two other graphs demonstrate temperature dependence of the self-diffusion coefficient for liquids in plane-parallel (dotted curve) and cylindrical (curve with circles) confined geometry.

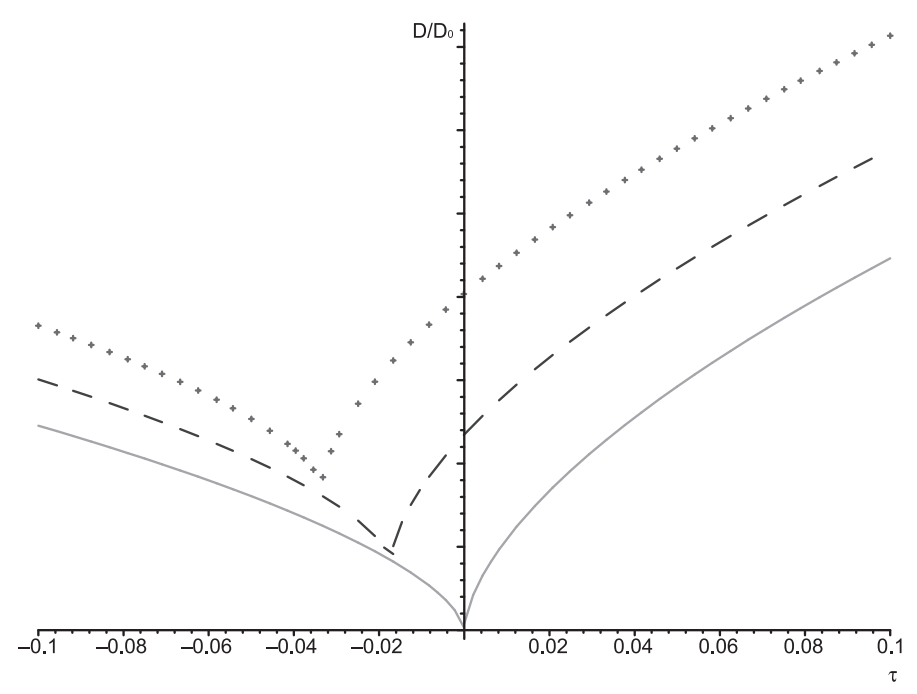

Figure 4. Temperature dependence of the self-diffusion coefficient.

An important peculiarity of the self-diffusion coefficient was also taken into account. Namely, its asymmetry (see figure 4), as it follows from the inequality $D_{+}^{*}>D_{-}^{*}$, where $D_{+}^{*}=D(|\tau|, L, k) / D_{0}^{+}$and $D_{-}^{*}=D(-|\tau|, L, k) / D_{0}^{-}$. There are two reasons for such an inequality $D_{+}^{*}>D_{-}^{*}$ : (i) change of sign of temperature deviation $\tau$ in expressions for $D( \pm|\tau|, L, k)$; (ii) inequality $D_{0}^{+} \neq D_{0}^{-}$of self-diffusion amplitudes in overcritical ( $T>T_{\mathrm{c}}$ ) and subcritical $\left(T<T_{\mathrm{c}}\right.$ ) regions. The same temperature dependence of the selfdiffusion coefficient (confirmed by independent theoretical calculations [22]) should be expected in experimental studies of diffusion processes in finite-size liquids.

\subsection{Dimensional crossover in finite-size liquid systems}

In this section we would like to pay attention to the following problem: how the results of 3D systems can be transferred to the results of $2 \mathrm{D}$ systems and vice versa. Of course, this transition cannot be very 
sharp; it should be smooth and without discontinuities, i.e., crossover-like. Let us call this 3D $\Leftrightarrow 2 \mathrm{D}$ transition as the dimensional crossover. To describe the dimensional crossover we shall take into account (i) an obvious fact that the critical exponents in 3D and 2D systems have quite different numerical values (see table 3); (ii) the results of computer experiments [23].

Table 3. Values of the critical exponents in 2D and 3D systems [10] (* Ornstein-Zernike approximation).

\begin{tabular}{|c|c|c|c|c|c|c|c|}
\hline $\begin{array}{c}\text { Space } \\
\text { dimen } \\
\text { siona } \\
\text { lity }\end{array}$ & $\begin{array}{c}\text { Theory or } \\
\text { experiment }\end{array}$ & $\alpha$ & $\beta$ & $\gamma$ & $\delta$ & $v$ & $\eta$ \\
\hline \hline & Landau & 0 & $1 / 2$ & 1 & 3 & $1 / 2^{*}$ & $0^{*}$ \\
\hline 2D & Ising model & $+0(\ln |\tau|)$ & $1 / 8$ & $7 / 4$ & 15 & 1 & $1 / 4$ \\
\hline 3D & Ising model & 0.125 & 0.3125 & 1.250 & 5 & 0.638 & 0.041 \\
\hline 3D & RG & 0.110 & 0.325 & 1.241 & 4.8 & 0.63 & 0.031 \\
\hline 3D & $\begin{array}{c}\text { Experimental } \\
\text { data }\end{array}$ & $0.11 \pm$ & $0.33 \pm$ & $1.23 \pm$ & $4.6 \pm$ & $0.63 \pm$ & $0.04 \pm$ \\
& 0.01 & 0.01 & 0.02 & 0.2 & 0.01 & 0.02 \\
\hline
\end{tabular}

Let us consider a confined liquid system with, say, the geometry of a plane-parallel layer. While reducing its width $L$ [or the number of monolayers $S$, see formulae (3)-(5) in our approach], the system will transfer from 3D to 2D geometry. This transition should result in the change of critical exponents of classical liquids which belong to the universality class of Ising model. The critical index $v$ will shift its value from 0.63 to 1.0 , the critical index $\gamma$ - from 1.24 to 1.75, etc. (table 3, [10]).

To receive a smooth transition between two fixed quantities we would like to use the idea of Kawasaki from the theory of mode coupling [24]. It permits to receive the so-called Kawasaki-like formula for the critical exponents inside 3D $\Leftrightarrow 2 \mathrm{D}$ dimensional crossover:

$$
y=n_{3}+\left[\frac{2}{\pi} \arctan (a x-b)-1\right] \frac{n_{3}-n_{2}}{2} .
$$

Equation (2.6) provides an interpolation for any effective critical exponent $y$ between its 3D and 2D values ( $n_{3}$ and $n_{2}$, respectively). Here, $x=L / L_{0}$ is the dimensionless width of the plane-parallel layer; $L_{0}$ is the linear size of the system in restricted geometry at which the crossover occurs (authors [23] consider $L_{0} \approx 2.4 \mathrm{~nm}$ for the slitlike pore); and $a, b$ are the dimensionless parameters characterizing the slope

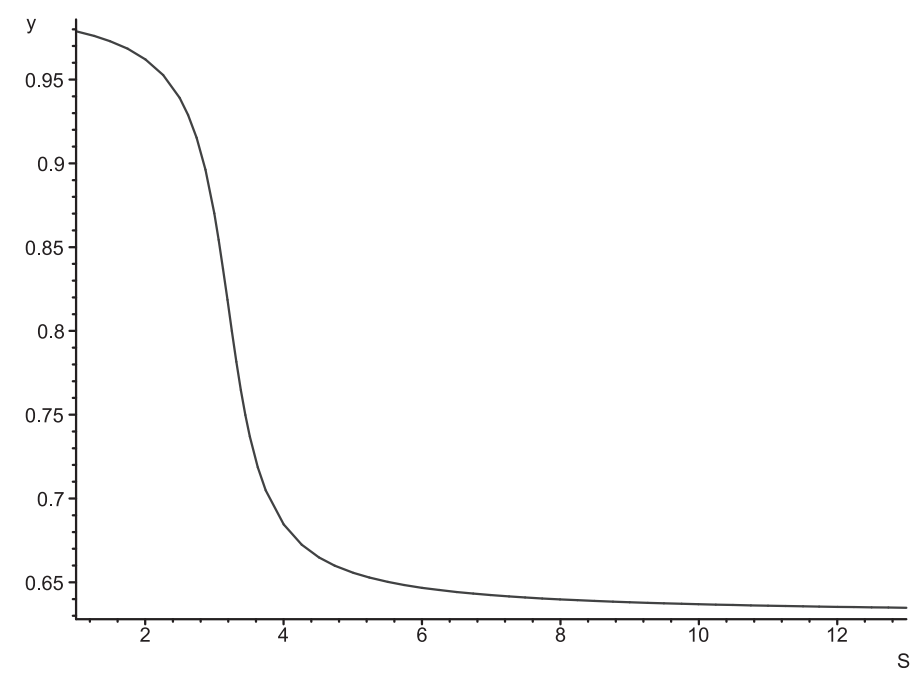

Figure 5. Dependence of the critical exponent $v$ on $S$. 
and position of the 3D $\Leftrightarrow 2 \mathrm{D}$ crossover along the $S$-axis. Figure 5 provides the theoretical dependence of the effective critical exponent $v$ on the number of monolayers $S$ in accordance with equation (2.6). Parameters $a=20$ and $b=8$ were chosen to fit the condition that the limiting 2D value of the critical exponent $v=1$ corresponds to a system containing approximately one monolayer.

The computer simulation experiment [23] demonstrates the dependence of the dimensionless pore critical temperature $T_{\mathrm{c}}^{\mathrm{pore}} / T_{3 \mathrm{D}}$ on the pore size, i.e., the thickness $H$ of a slitlike pore or radius $R$ of a cylindrical pore (figure 6). Closed squares and open circles correspond, respectively, to slitlike and cylindrical pores filled with water molecules. Dashed lines show the critical temperatures of the bulk 3D water (upper line) and the 2D water (lower line). The lowest square corresponds to the critical temperature of nearly 2D water in slitlike pore with its thickness $H=0.5 \mathrm{~nm}$. This value of thickness $H$ refers to nearly one monolayer plane with taking into account that the diameter of water molecule is equal to $d \approx 0.3 \mathrm{~nm}$.

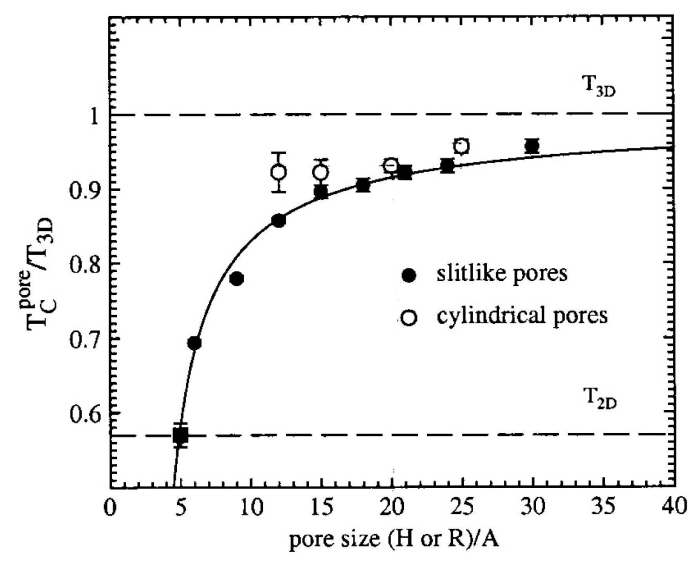

Figure 6. Size dependence of the pore critical temperature (computer experiment [23]).

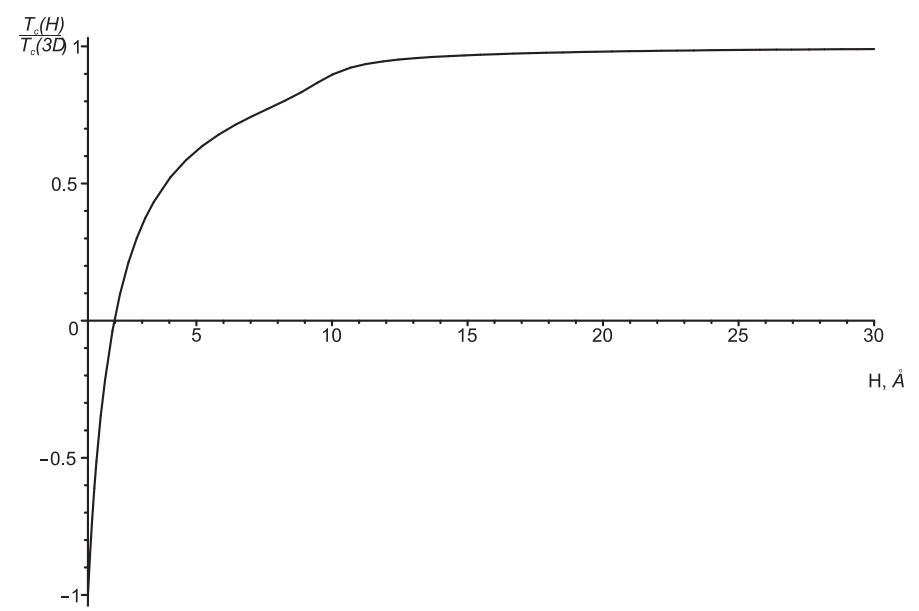

Figure 7. Size dependence of the critical temperature in slitlike pore [finite-size scaling + formula (2.6) for $v$ ].

The finite-size scaling theory $[6-8,11,16,25]$ provides the following formula for the shift of the critical temperature $T_{\mathrm{c}}^{\text {pore }}=T_{\mathrm{c}}(H)$ in comparison with its bulk value $T^{3 \mathrm{D}}=T_{\mathrm{c}}(\infty)$ :

$$
\tau^{*}=\left[T_{\mathrm{c}}(H)-T_{\mathrm{c}}(\infty)\right] / T_{\mathrm{c}}(\infty) \sim H^{-\frac{1}{v}}
$$


The quite equivalent formula is as follows:

$$
\frac{T_{\mathrm{c}}(H)}{T_{\mathrm{c}}(\infty)}=1+k H^{-\frac{1}{v}}
$$

where $k$ is the coefficient of proportionality.

In order to check our interpolation formula (2.6) using the results of computer experiment [23], we substituted the size dependence of the critical exponent $v(H)$ [see (2.6) and figure 5] into the formula (2.8). It yields the size dependence of the critical temperature $T_{\mathrm{c}}(H)$ in slitlike pores shown by figure 7 . The agreement between the computer experiment data and theoretical calculations seems to be quite good. An additional curvature near the $3^{\text {rd }}$ left-hand point (figure 6 ) is even observed in the theoretical dependence $T_{\mathrm{c}}(H)$ in figure 7 .

It is interesting to stress that the beginning of the dimensional crossover from 3D to 2D critical behavior takes place at the slitlike pore thickness $H^{\text {cross }} \approx 2.4 \mathrm{~nm}$. This value of $H^{\text {cross }}$ is mentioned in [23] and can be observed in figure 7 . It corresponds to approximately 8 monolayers of water molecules in a slitlike pore.

\section{Neutron studies and its medical applications}

The method of quasi-elastic neutron scattering (QENS) is a powerful physical method of studying the dynamic properties of liquids and aquatic suspensions of membrane mesostructures [19]. In particular, the direct relationship between the change of the diffusion coefficient $D$ of water molecules and the sensitivity of biological cells to antitumor drugs was examined based on the theoretical calculations and precise QENS experimental information in [26,27].

The corresponding theoretical background includes both contributions of the collective and singleparticle diffusion of water molecules. The width of the quasi-elastic peak of slow neutron scattering $\triangle E\left(q^{2}\right)$ can be presented by the following formula [19, 26, 27]:

$$
\triangle E\left(q^{2}\right)=2 \hbar D^{\text {coll }} q^{2}+\frac{2 \hbar}{\tau_{0}}\left[1-\frac{\exp (-2 W)}{1+\left(D-D^{\text {coll }}\right) q^{2} \tau_{0}^{-1}}\right] .
$$

Here, $D^{\text {coll }}$ is the collective contribution to the diffusion coefficient of water molecules, $D$ is the diffusion coefficient with collective and single-particle contributions, $W$ is the energy of activation (Debay-Waller factor), $q=(4 \pi / \lambda) \sin \theta / 2$ is the change of neutron wave vector, $\theta$ is the scattering angle of a neutron beam, $\tau_{0} \approx 10^{-10} \div 10^{-12} \mathrm{~s}$ is the mean lifetime of hydrogen bonds.

Thus, the width of the neutron quasi-elastic scattering peak $\triangle E\left(q^{2}\right)$ makes it possible to calculate $D$ and $\tau_{0}$, i.e., the dynamic characteristics of interaction between water molecules and its environment.

Neutron analysis of the width $\triangle E\left(q^{2}, \tau\right)$ in aquatic solutions of plasmatic membranes of tumor cells is a promising biomedical direction of studies near structural phase transitions such as the cell proliferation [28]. It is known (see, for example, [29-31]) that the mobility of polar groups as well as rotational mobility of carbohydrate chains changes near the phase transitions of cell structures. Cooperative processes in the membranes which are isomorphous to phase transitions in liquid mixtures play an important role in the mechanisms of ionic transport, amplification of external stimuli, diffusion processes in membrane memory, etc.

The plasmatic membranes of cells are typical mesostructures with a characteristic thickness about $10 \mathrm{~nm}$. Therefore, in accordance with the hypothesis of dynamic scaling and expressions for kinetic coefficients in spatially limited liquids (see the previous results in this paper), we may write the following formula for the width of quasi-elastic peak of slow neutron scattering in slitlike pores with its thickness $H$ :

$$
\triangle E\left(q^{2}, \tau\right)=\triangle E_{0}\left(q^{2}\right)\left\{(G / S)^{\frac{1}{v}}+\left[1+(G / S)^{\frac{1}{v}}\right]\left(\xi^{*}\right)^{-\frac{1}{v}} \operatorname{sign} \tau\right\}^{\gamma} .
$$

Here, $\triangle E_{0}\left(q^{2}\right)=2 \hbar D_{0} q^{2}$ and $D_{0}$ are the amplitudes of the width of quasi-elastic peak and diffusion coefficient. 
The main theoretical result of equations (3.2) is as follows: the width $\Delta E$ of quasi-elastic peak of slow neutrons scattering narrows (as well as the diffusion coefficient $D$ decreases), while the process of proliferation with increasing $S \sim H$ takes place in the mesostructure of plasmatic membranes.

Such a size dependence of width $\triangle E$ in bulk aquatic suspensions of plasmatic membranes for the case $H / \xi \leqslant 1$ can be explained as follows. If $H>H_{\mathrm{D}}$, i.e., for sizes $H$ larger than the characteristic size $H_{\mathrm{D}}$ at which the dynamic crossover region is realized [18, 32], one has the following expression: $\triangle E\left(q^{2}, \tau\right) / \triangle E_{0}\left(q^{2}\right) \sim H^{-\gamma / v} \approx H^{-2}$, while $\gamma / v=2-\eta \approx 1.96$. In the fluctuation region $\left(H<H_{\mathrm{D}}\right)$, at which singular parts of the kinetic Onsager coefficients should be taken into account, the size dependence of $\triangle E$ becomes smoother: $\triangle E\left(q^{2}, \tau\right) / \triangle E_{0}\left(q^{2}\right) \sim H^{(-\gamma+v) / v} \approx H^{-1}$.

Thus, the studies of the width of quasi-elastic peak of slow neutron scattering depending on the thickness of the membrane mesostructures, which changes in the process of the cell proliferation, can serve as an additional diagnostic test for the process of tumor formation.

\section{Conclusion}

In this review paper, we have investigated the specific features of mesoscale liquids in the critical region. We have shown that, having taken into account the actual factors of a liquid system at restricted geometry, such as number monolayers in confined systems, low crossover dimensionality, etc., the hypothesis of the universality may be essentially generalized for the finite-size systems of different nature. There is another important problem discussed in this paper, namely, the $3 D \Leftrightarrow 2 \mathrm{D}$ dimensional crossover. We have proposed the interpolation formula (2.6) to get a smooth transition from 3D to 2D values of the critical exponent $v$ confirming the results of computer experiments. We also hope that the further development of the physics of the 1st and continuous the 2nd order phase transitions will make a great contribution to biomedical applications; especially it will help to formulate new ideas and methods of diagnostics and to prevent the process of tumor formation.

\section{References}

1. Patashinskii A.Z., Pokrovskii V.L., Fluctuation theory of phase transitions, Pergamon Press, Oxford, 1979.

2. Wilson K.G., Kogut J., Phys. Rep. C, 1974, 12, No. 2, 75-199; doi 10.1016/0370-1573(74)90023-4

3. Wilson K., Kogut J., Renormalization Group and $\varepsilon$-Expansion, Mir, Moscow, 1980.

4. Yukhnovskii I.R., Phase Transitions of the Second Order. Collective Variables Method, World Scientific, Singapore, 1987.

5. Kozlovskii M.P., Influence of external field on critical behavior of 3-dimentional systems, Galytskii drukar, Lviv, 2012.

6. Fisher M.E., In: Proceedings of the International School of Physics “Enrico Fermi”, M.S. Green (Ed.), Academic, New York, 1971.

7. Finite Size Scaling and Numerical Simulation of Statistical Systems, V. Privman (Ed.), World Scientific, Singapore, 1990.

8. Binder K., Annu. Rev. Phys. Chem., 1992, 43, 33-59; doi 10.1146/annurev.pc.43.100192.000341

9. Anisimov M.A., Voronel A.V., Gorodetskii E.E., Soviet Physics JETP-USSR, 1971, 33, 605-612.

10. Anisimov M.A., Critical Phenomena in Liquids and Liquid Crystals, Gordon and Breach Science Publishers, 1991.

11. Chalyi A.V., J. Mol. Liquids, 1993, 58, 179-195; doi 10.1016/0167-7322(93)80066-5

12. Chalyy K.O., Bulavin L.A., Chalyi A.V., J. Phys. Stud., 2005, 9, 1, 66-70.

13. Bulavin L.F., Chalyy K.O., Bull. Kyiv Uni. Ser.: Physics and Mathematics, 2006, 1, 328-337.

14. Chalyy K.O., Ukr. J. Phys., 2005, 50, 10, 1134-1138.

15. Chalyi A.V., Zaitseva O.V., Bull. Kyiv Uni. Ser.: Physics and Mathematics, 2009, 1, 366-370.

16. Chalyi A.V., Lebed A.G., Non-homogeneous Liquids Near the Critical Point and the Boundary of Stability and Theory of Percolation in Ceramics, Harwood Academic Press, London, 1993.

17. Chalyi A.V., Tsekhmister Ya.V., Chalyy K.O., Processes of Ordering and Self- Organization in Fluctuation Models of Open Systems, Vipol, Kyiv, 2001.

18. Onuki A., J. Chem. Phys., 1986, 85, 1122-1125; doi 10.1063/1.451308

19. Bulavin L.A., Karmazina T.V., Klepko V.V., Slisenko V.I., Neutron Spectroscopy of Condensed Systems, Academperiodyka, Kyiv, 2005. 
20. Kimball M.O., Mooney K.P., Gasparini F.M., Phys. Rev. Lett., 2004, 92, 115301; doi 10.1103/PhysRevLett.92.115301

21. Sysoev V.M., Chalyi A.V., Teor. Mat. Fiz., 1976, 26, 126 [Theor. Math. Phys., 1976, 26, 82; doi 10.1007/BF01038260].

22. Koch W., Dohm V., Phys. Rev. E, 1998, 58, R1179-R1182; doi 10.1103/PhysRevE.58.R1179

23. Brovchenko I., Oleinikova A., In: Handbook of Theoretical and Computational Nanotechnology, 2005, Vol. 1, P. 198.

24. Kawasaki K., In: Phase Transitions and Critical Phenomena, Vol. 5a, C. Domb, M.S. Green (Eds.), Academic Press, New York, 1976, P. 165-403.

25. Chalyi A.V., Lukomskii V.P., Gandzha I.S., Tsekhmister Ya.V., Chalyy K.A., Nonlinear Processes in Physics: Oscillations, Waves, Self-Organization, Chetvertaya khvylja, Kyiv, 2004.

26. Bulavin L.A., Chekhun V.F., Chalyy K.A. et al., Physics of the Alive, 2004, 12, 1, 94-100.

27. Bulavin L.A., Vyshnevskii I.M., Chekhun V.F., Bila R.V., Tryndyak V.P., Chalyy K.O., Rep. Nat. Acad. Sci. Ukraine, 2004, 7, 176-181.

28. Oncology. Selected Lectures for Students and Physicians, V.F.Chekhoun (Ed.), Zdorovje Ukrainy, Kyiv, 2010.

29. Chalyi A.V., Tsekhmister Ya.V., Agapov B.T. et al. Medical and Biological Physics, 2nd edition, Nova Knyga, Vinnytsia, 2013.

30. Kostyuk P.G., Grodzinskii D.M., Zima V.L., Mogoura I.S., Sidoryk E.P., Shouba M.F., Biophysics, Vyscha shkola, Kyiv, 1988.

31. Roubin A.B., Biophysics, Vol. 1, 2, Vysshaya shkola, Moscow, 1987.

32. Chalyi O.V., Khrapiichuk G.V., Chernenko L.M., Chalyi K.O., Zaitseva O.V., Ukr. J. Phys., 2010, 55, 10, 1113-1124. 


\title{
Класи універсальності та критичні явища в обмежених рідинних системах
}

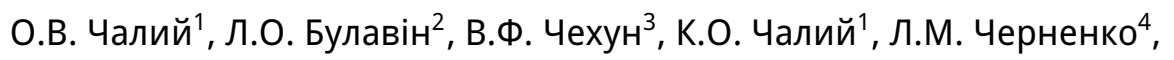

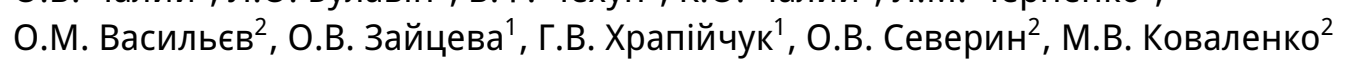 \\ 1 Національний медичний університет імені О.О.Богомольця \\ 2 Київський національний університет імені Тараса Шевченка \\ 3 Інститут експериментальної патології, онкології та радіології імені Кавецького НАН України \\ ${ }^{4}$ Інститут хімії поверхні імені О.О.Чуйко НАН України
}

Подібність універсальної поведінки систем великих розмірів різної природи вимагає однаковості таких основних умов: вимірності простору, числа компонент параметра порядку; коротко- або далекодіючих міжмолекулярних взаємодій; симетрії флуктуаційної частини термодинамічного потенціалу. Основні умови подібності універсальної поведінки для просторово обмежених систем доповнюються однаковими додатковими умовами: кількістю моношарів у напрямку просторового обмеження системи; нижньою кросоверною вимірністю, тобто геометричною формою обмеженого об'му; граничними умовами на обмежуючих поверхнях; фізичними властивостями, які розглядаються. Метою цієї оглядової статті було вивчення умов подібності універсальної поведінки процесів дифузії у просторово обмежених рідинних системах. Особливу увагу було приділено ефектам просторової дисперсії і нижньої кросоверної вимірності. Це дозволило отримати правильні ненульові вирази для коефіцієнта дифузії у критичній точці 3 урахуванням конкретної геометричної форми обмеженого об'єму рідини. При розгляді проблеми $3 D \Leftrightarrow$ 2D вимірного кросовера були отримані оригінальні результати для плавного переходу критичних індексів за допомогою підходу, схожого на метод Кавасакі в теорії динамічного скейлінгу. Це призвело до гарного узгодження між даними комп'ютерного експерименту і теоретичними розрахунками залежності величини критичної температури $T_{\mathrm{c}}(H)$ води від товщини щілиноподібних пор. Було досліджено ширину квазіпружного піку розсіяння повільних нейтронів поблизу структурного фазового переходу в водних суспензіях плазматичних мембран (мезоструктур з типовою товщиною до 10 нм). Доведено, що ширина квазіпружного піку розсіяння нейтронів повинна зменшитися внаслідок процесу клітинної проліферації, тобто із збільшенням розміру мембрани (у тому числі товщин мембран). Таким чином, нейтронні дослідження можуть слугувати додатковим діагностичним тестом для виявлення процесу утворення пухлини.

Ключові слова: класи універсальності, обмежені рідинні системи, просторова дисперсія, нижня кросоверна вимірність, вимірний кросовер, ширина квазіпружного піку, нейтронне розсіяння 